\title{
PENGARUH KONSENTRASI ASAM ALKOHOL TERHADAP HASIL PEMERIKSAAN BASIL TAHAN ASAM METODE ZIEHL NEELSEN
}

\author{
The Effect Of Concentration Of Alcohol Acid On The Results Of Basic Resistance Based \\ On Ziehl Neelsen Method \\ Reski Amelia ${ }^{1}$, Sitti hadijah ${ }^{2}$, Muhammad Nasir ${ }^{3}$ \\ ${ }^{1}$ D4 Teknologi Laboratorium Medik Poltekkes Kemenkes Makassar \\ 2,3 Jurusan Teknologi Laboratorium Medik Poltekkes Kemenkes Makassar
}

Koresponden: shitaku2975@gmail.com

\begin{abstract}
Tuberculosis $(T B)$ is a disease that is still a major cause of death in the world, especially in Indonesia. enforcement of TB diagnosis through microscopic examination is the main key to start treatment. Globally, sputum examination is done by using the Ziehl Neelsen method which consists of carbol fuchsin, alcoholic acid, methylen blue. The purpose of this study was to see how much influence the concentration of Alcoholic Acid on the results of Ziehl Neelsen's method of Acid Resistant Basil. This study uses variations in the concentration of 1\% Alcoholic Acid, 3\% Alcoholic Acid, 6\% Alcoholic Acid, 9\% Alcoholic Acid, 12\% Alcoholic Acid. The number of samples as much as 3 with the number of treatments as much as 5, and making preparations by triplo, then the preparations as much as 45. The results of smear staining with the Ziehl Neelsen method is best to use 3\% alcoholic acid. The conclusion that can be drawn is the concentration of alcoholic acid used in BTA staining Ziehl Neelsen method is very influential on the BTA examination results. Suggestion, The use of $3 \%$ concentration is very in accordance with the specified IUALTD standards.
\end{abstract}

Key words: BTA Microscopic Examination, Alcoholic Acid

\begin{abstract}
ABSTRAK
Tuberkulosis (TB) merupakan salah satu penyakit yang sampai saat ini masih menjadi penyebab utama kematian di dunia terutama di indonesia. penegakan diagnosis TB melalui pemeriksaan mikroskopis merupakan kunci utama untuk memulai pengobatan. Secara global di sepakati pemeriksaan dahak dengan menggunakan metode Ziehl Neelsen yang terdiri dari carbol fuchsin, asam Alkohol, Methylen Blue. Tujan penelitian ini adalah untuk melihat seberapa besar pengaruh konsentrasi Asam Alkohol terhadap hasil pemeriksaan Basil Tahan Asam metode Ziehl Neelsen. Penelitian ini menggunakan variasi konsentrasi Asam Alkohol 1\%, Asam Alkohol 3\%, Asam Alkohol 6\%, Asam Alkohol 9\%, Asam Alkohol 12\%. Jumlah sampel sebanyak 3 dengan jumlah perlakuan sebanyak 5 , dan pembuatan preparat dengan cara triplo, maka di hasilkan preparat sebanyak 45. Hasil pewarnaan BTA dengan metode Ziehl Neelsen yang paling baik menggunakan Asam Alkohol 3\%. Kesimpulan yang dapat diambil adalah konsentrasi asam alcohol yang digunakan dalam pewarnaan BTA metode Ziehl Neelsen sangat berpengaruh terhadap hasil pemeriksaan BTA. Saran Penggunaan konsentrasi 3\% sudah sangat sesuai dengan standar IUALTD yang ditetapkan
\end{abstract}

Kata kunci : Pemeriksaan Mikroskopis BTA, Asam Alkohol 


\section{PENDAHULUAN}

Tuberculosis (TB) adalah suatu penyakit infeksi yang disebabkan oleh bakteri Mycobacterium tuberculosis. Bakteri ini merupakan bakteri basil yang sangat kuat sehingga memerlukan waktu lama untuk mengobatinya. Bakteri ini lebih sering menginfeksi organ paru-paru dibandingkan bagian lain tubuh manusia. Tuberkulosis (TB) membunuh 5000 orang setiap hari. Dampak sosial dan ekonomi menghancurkan, termasuk kemiskinan, stigma dan diskriminasi. sementara dunia telah berkomitmen untuk mengakhiri epidemi TB pada tahun 2030, tindakan dan investasi tidak sesuai dengan retorika politik (Nizar, 2017)

Berkembangnya penyakit TB di Indonesia tidak lain berkaitan dengan memburuknya kondisi sosial ekonomi, belum optimalnya fasilitas pelayanan kesehatan masyarakat, meningkatnya jumlah penduduk yang tidak mempunyai tempat tinggal dan adanya epidemi dari infeksi HIV. Hal ini juga tentunya mendapat pengaruh besar dari daya tahan tubuh yang lemah/menurun, dimana penderita TBC akan mengalami anoreksia

Indonesia merupakan negara dengan pasien TB terbanyak ke 5 di dunia setelah India, Cina, Afrika Selatan dan Nigeria. Pada tahun 2009 prevalensi HIV pada kelompok TB di indinesia sekitar $2.8 \%$ kekebalan ganda kuman TB terhadap obat anti TB-MDR (Multi Drug Resistence) diantara kasus TB baru sebesar 2\%, sementar MDR diantara kasus penobatan ulang sebesar $20 \%$ (WHO,2009).

Sesuai data WHO Global Report 2016, Indonesia sekarang menempati posisi kedua dengan beban TBC Tertinggi di dunia, tren insiden kasus TBC di indonesia tidak pernah menurun, masih banyak kasus yang

Vol. 10 No. 2, November 2019

DOI: https://doi.org/10.32382/mak.v10i2.1266 belum terjangkau dan terdeteksi kalaupun terdetaksi dan telah di obat tetapi belum di laporkan (WHO, 2018).

Hingga saat ini, belum ada satu negara pun yang bebas TB. Angka kematian dan kesakitan akibat kuman Mycobacterium Tuberculosis ini pun tinggi. Tahun 2009, 1,7 juta orang meninngal karena TB 600.000 orang di antaranya perempuan sementara ada 9,4 juta kasus baru TB 3,3 juta di antaranya perempuan. Sepertiga dari populasi dunia sudahtertular dengan TB dimana sebagian besar penderita TB adalah usia produktif (15-50 tahun) (KemenKes RI, 2017).

Metode yang digunakan di laboratorium pelayanan kesehatan pada pewarnaan Basil Tahan Asam yaitu metode pewarnaan Kinyoun Gabbet dimana pada pewarnaan ini Ditemukannya kuman tahan asam dalam sputum penderita seringkali dihubungkan dengan penyakit tuberkulosis. Sebenarnya hasil ini hanya menunjukkan adanya kuman tahan asam dan kuman yang ditemukan ini mungkin juga bukan kuman tuberkulosis. Pewarnaan Khusus adalah Pewarnaan yang dipakai untuk mewarnai bagian-bagian sel kuman atau kuman tertentu yang sukar di warnai dengan pewarnaan biasa. Salah satu metode yang sampai saat ini masih digunakan untuk mencari kuman BTA adalah pewarnaan Ziehl Neelsen, dimana pada dinding bakteri yang tahan asam mempunyai lapisan lilin dan lemak yang sukar tembus cat. Oleh karena pengaruh fenol dan pemanasan maka lapisan lilin dan lemak itu dapat tembus cat basic fuchsin. Pada waktu pencucianlapisan lilin dan lemak yang terbuka akan merapat kembali. Pada pencucian dengan asam alkohol, pada bakteri tahan asam warna fuchsin tidak lepas,sedangkan pada bakteri tidak 
tahan asam akan luntur dan mengambil warna biru dari methylen blue.

Salah satu larutan yang digunakan untuk melunturkan zat warna dari carbol fuchsin pada pewarnaan ziehl Neelsen adalah konsentrasi Asam Akohol 3\%, komposisi asam alkohol yaitu $\mathrm{HCl}$ (asam klorida) pekat dan alkohol 96\%. Pada konsentrasi asam alkohol untuk pelunturan zat warna carbol fuchsin, sehingga peneliti tertarik meneliti "Pengaruh Konsentrasi Asam Alkohol Terhadap Hasil Peneriksaan Basil Tahan Asam Metode Ziehl Neelsen". Penelitian ini bertujuan untuk Untuk menentukan pengaruh hasil pemeriksaan preparat BTA terhadap pewarnaan Ziehl Neelsen menggunakan Konsentrasi Asam Alkohol 1\%, 3\%, $6 \%, 9 \%$ dan $12 \%$.

\section{METODE}

\section{Jenis Penelitian, waktu dan tempat penelitian}

Penelitian dilakukan dengan jenis penelitian eksperimen semu dengan rancangan dalam menentukan seberapa besar pengaruh hasil pemeriksaan preparat BTA terhadap pewarnaan Ziehl Neelsen menggunakan konsentrasi Asam Alkohol. Penelitian ini dilaksanakan pada bulan februari sampai dengan Maret 2019 di Kampus jurusan Analis kesehatan politeknik Kesehatan Makassar

\section{Populasi dan Sampel}

Populasi dalam penelitian ini adalah penderita tuberculosis paru (TB paru) dengan hasil pemeriksaan dahak mikroskopis (+)/positif yang berobat di Balai Besar Kesehatan Paru Masyarakat Makassar (BBKPM). Sampel yang digunakan dalam penelitian ini adalah Konsentrasi Asam Alkohol

\section{Teknik Pengambilan Sampel}

Sampel di ambil secara purposive sampling dengan kriteria sampel Pasien dengan hasil pemeriksaan BTA positif

\section{Teknik Pengumpulan Data}

1. Pembuatan preparat

Diambil kaca sediaan yang bersih, bebas lemak dan tidak ada goresan,siapkan sebuah kaca sediaan yang diberi tanda ukuran $2 X 3 \mathrm{~cm}$ sebagai pola,Diletakkan pola dibawah kaca sediaan,Lampu spritus dinyalakan, Dengan menggunakan lidi steril lalu di ambil bagian sputum yang kental berwarna putih kekuningan atau putih kehijauan, lalu diletakkan pada kaca, Sputum diratakan seperti terlihat pada gambar,Dimasukkan lidi kedalam botol yang berisi lisol,Kemudiaan sediaan dikeringakan pada suhu ruangan

2. Pewarnaan preparat

Setelah kering fiksasi terlebih dahulu,Letakkan sediaan di atas rak pewarnaa dengan apusan menghadap keatas,Tuangkan carbol fuchsin sampai menutupi seluruh permukaan kaca sediaan,Panaskan kaca sediaan secara hati hati dengan cara melewatkan nyala api pada bagian bawah kaca sehingga keluar uap (jangan sampai mendidih) sediaan di diamkan selama 5 menit,Sediaan di cuci dengan air mengalir,Tuangkan asam alkohol pada perlakuan $1=1 \%$, perlakuan $2=3 \%$, perlakuan $3=6 \%$, perlakuan $4=9 \%$ dan perlakuan $5=12 \%$ di atas kaca sediaan sampai warna merah dari fuchsin hilang hilang, masing masing perlakuan di cuci dengan air mengalir,Tuangkan larutam methylen blue $0.3 \%$ di atas sediaan dan biarkan selam 10-20 detik.,Sediaan di cuci dengan air mengalir dan keringkan pada suhu kamar.

3. Pemeriksaan preparat

Sediaan yang sudah kering diperiksa dibwah mikroskop, Teteskan satu tetes oil emersi di atas sediaan,Periksa dengan lensa okuler 
10x dan lensa objektif 100x,Carilah basil tahan asam yang berwarna Merah dengan latara belakang Biru,Periksa paling sedikit lapangan pandang dengan cara menggeserkan sediaan dari kiri ke kanan atau dari kiri ke kanan pada garius lurus. Seperti yang terlihat pada tabel 1.

\section{HASIL}

Hasil dari pengaruh Konsentrasi Asam Alkohol terhadap hasil pewarnaan Basil Tahan Asam menggunakan Metode Ziehl Neelsen Konsentrasi Asam Alkohol 1\%, Asam Alkohol 3\%, Asam Alkohol 6\%, Asam Alkohol 9\%, Asam Alkohol 12\%. Dari hasil pemeriksaan maka di dapatkan hasil pemeriksaan sebagai berikut:

\section{Karakteristik Sampel}

Karakteristik sampel merupakan sampel sputum positif, yang terdiri dari positif 1, positif 2, dan positif 3 . Yang merupakan sampel dari penderita Tuberculosis Paru Berdasarkan pemeriksaan Basil Tahan Asam menggunakan konsentrasi Asam Alkohol $1 \%$, Asam Alkohol 3\%, Asam Alkohol 6\%, Asam Alkohol 9\%, Asam Alkohol 12\%, Di dapatkan hasil terbaik pada konsentrasi Asam Alkohol 3\% sedangkan hasil yang tidak baik yaitu konsentrasi Asam Alkohol 12\%.

\section{Uji Normalitas Data}

Uji normalitas adalah sebuah uji yang dilakukan dengan tujuan untuk menilai sebaran data tersebut berdistribusi normal ataukah tidak.Uji normalitas berguna untuk menentukan data yang telah dikumpulkan berdistribusi normal atau diambil dari populasi normal.

Normalitas dapat menggunakan uji kolmogorov smirnov jika responden
> 50 sampel, karena pada peneltian ini sampel hanya 3 maka, uji normalitas data menggunakan uji Shapiro-wil.

Berdasarkan pada tabel 3 dapat di lihat bahwa nilai signifikansi (sig) data pemeriksaan positif $1=0,814$, positif 2 $=0.146$, positif $3=0.146$. Ketiga varians data diatas menunjukan nilai Sig. > 0,05. Dengan demikian sebaran data sampel pada penelitian ini terdistribusi normal.

Berdasarkan hasil uji anova one way didapatkan bahwa nilai signifikan Uji Anova Two Way sebesar 0,001 < 0,05 dengan demikian dapat diambil kesimpulan bahwa ada pengaruh konsentrasi asam alkohol terhadap Hasil Pewarnaan BTA metode Ziehl Neels

\section{Post Hoc Test}

Post Hoc Test adalah Uji Lanjut Statistik yang bertujuan untuk melihat perbedaan signifikan antara beberapa varians data secara lebih detail

Berdasarkan tabel 4. hasil analisis menunjukkan bahwa antara konsentrasi asam alkohol $1 \%$ dengan $3 \%$ tidak terdapat Perbedaan terhadap hasil pewarnaan BTA $($ Sig. $=0,217)$ tetapi nilai mean diffencenya cukup rendah yaitu (-1,00). Untuk Konsentrasi antara $1 \%$ dengan $6 \%$ tidak terdapat perbedaan hasil Pewarnaan BTA (Sig. $=0,926)$ perbedaan nilai meannya cukup rendah $(-0,33)$, konsentrasi antara $1 \%$ dengan 9\% tidak terdapat perbedaan hasil pewarnaan BTA yang significant (1.000) dengan nilai mean difference 0.00 , sementara konsentrasi $1 \%$ dengan $12 \%$ terdapat perbedaan pewarnaan BTA yang significant (0.009) dengan nilai difference cukup tinggi yaitu 2,00. 
Konsentrasi antara 3\% dengan 6\% juga tidak terdapat perbedaan.

Hasil Pewarnaan BTA (Sig. = 0,546) namun hasil Post Hoc Test (Uji Lanjut) menunjukkan perbedaan nilai Mean Differencenya hanya sebesar 0,67, konsentrasi 3\% dengan 9\% tidak terdapat perbedaan hasil pewarnaan BTA tetapi nilai meannya cukup tinggi $(1,00)$, sementara konsentrasi $3 \%$ dan $12 \%$ memiliki berbedaan yang sangat significant terhadap hasil pewarnaan BTA (0.001) dan nilai mean differencenya cukup tinggi $(3,00)$. Konsentrasi $6 \%$ dan $9 \%$ tidak memiliki perbedaan yang significant terhadap hasil pewarnaan BTA Dan nilai mean differencenya adalah $(0,33)$, sementara untuk konsentrasi $6 \%$ dan $12 \%$ terdapat perbedaan yang significant terhadap hasil pewarnaan BTA (0.009) dan nilai mean differencenya cukup tinggi (2,33). Konsentrasi $9 \%$ dan $12 \%$ terdapat perbedaan nilai yang significant terhadap hasil pewarnaan BTA $(0,009)$ Dan nilai mean differencenya cukup tinggi $(2,00)$. Pada konsentrasi $12 \%$ dengan $1 \%$ memiliki perbedaan yang significant 0.009 dan nilai mean differencenya cukup rendah yaitu -2.00 . $12 \%$ dengan $3 \%$ memiliki perbedaan yang significan 0,001 dengan nilai mean difference $-3,00$. Pada konsentrasi $6 \%$ terdapat nilai significan 0.004 dan nilai mean difference cukup rendah (2.33), pada konsentrasi 9\% terdapat perbedaan nilai significant sebesar 0,009 dan mean difference $-0,22$

\section{PEMBAHASAN}

Penelitian ini menggunakan variasi Konsentrasi Asam Alkohol 1\%. Asam Alkohol 3\%, Asam Alkohol 6\%, Asam Alkohol 9\%, Asam Alkohol 12\%. Untuk melihat adanya pengaruh konsentrasi Asam alkohol terhadap hasil pewarnaan Basil Tahan Asam Menggunakan metode Ziehl Neelsen.

Menurut (Kumala, 2006), Adanya fenol dan pemanasan yang berfungsi membantu membuka lapisan lilin tersebut maka dinding sel yang tebal mampu mengikat karbol Fuchsin. Dinding Sel Bakteri BTA mempunyai lapisan lilin dan asam mikolat, lipid yang sukar ditembus oleh cat, sedangkan methylen blue konsentrasinya cukup sehingga warna merah pada BTA terlihat jelas.

Secara global telah di sepakati pemeriksaan mikroskopik dahak dengan menggunakan pewarnaan metode ziehl Neelsen. Zat warna yang digunakan dalam pewarnaan ziehl neelsen adalah carbol fuchsin, asam Alkohol, dan methylen blue. Carbol fuchsin merupakan basa yang di larutkan di larutkan dalam fenol digunakan sebagai pelarut untuk membantu pemasukan zat warna kedalam sel bakteri sewaktu proses pemanasan. Fungsi pemanasan untuk melebarkan pori pori lemak BTA di cuci dengan larutan dekolorisasi yaitu asam alkohol sehingga zat warna pertama mudah di lunturkan.

Faktor yang mempengaruhi untuk mendapatkan hasil pemeriksaan laboratorium mikroskopik dahak yang bermutu, antara lain sumber daya manusia, peralatan terutama mikroskop, serta reagensia larutan pewarna ziehl neelsen.

Saat ini terdapat banyak reagen yang beredar dengan kualitas yang bervariasi. Terlebih lagi dengan adanya kebijakan otonomi daerah menyebabkan kabupaten atau kota dan propinsi mempunyai wwenang untuk melakukan pengadaan reagen 
sendiri. Agar hasil pemeriksaan mikroskopik BTA terjamin mutunya untuk itu peru dilakukan standirisasi reagen (Depkes, 2008)

Hasil penelitian Alvinova (2016) tentang perbandingan variasi carbol fuchsin dan methylen blue pada pewarnaan BTA mendapatkan hasil yang paling baik adalah carbol fuchsin $1 \%$ dengan methylen blue $0,1 \%$, pada penelitiannya tetap menggunakan konsentrasi asam alkoho $3 \%$.

Reagen carbol fuchsin $1 \%$ konsentrasinya tinggi, larutannya pekat dan kuat sehingga dinding sel yang mempunyai lapisan lemak mampu mengikat warna merah pada sel tersebut, konsentrasi Asam Alkohol 3\% juga memiliki konsentrasi yang cukup sehingga dapat melunturkan zat warna carbol fuchsin, sedangkan methylen blue konsentrasinya cukup dan terlihat kontras sehingga warna merah BTA dapat terlihat jelas, (Fujiki, A. 2009).

Dari hasil penelitian yang telah di lakukan, di Laboratorium kampus jurusan Analis Kesehatan Politekniknik Kesehatan Makassar di dapatkan bahwa konsentrasi Asam Alkhol berpengaruh terhadap hasil pewarnaan Basil Tahan Asam metode Ziehl Neelsen ( $\rho$. 0,001) dengan demikian Hipotesis Alternatif (Ha) pada penelitian ini diterima

Mutu hasil pemeriksaan dahak secara mikroskopis perlu di dukung oleh reagen yang berkualitas. Tahun 2013 global laboratory initiative (GLI) yang merupakan kelompok kerja di bawah naungan WHO mengeluarkan pedoman mikroskopis TB yang menyebutkan bahwa penggunaan carbol fuchsin $1 \%$, Asam Alkohol 3\%, methylen blue
$0.1 \%$. Hal tersebut di nyatakan dalam surat edaran nomor HK03.03/I/4002/2014 Tentang "perubahan konsentrasi carbol fuchsin untuk pemeriksaan mikroskopik TB “ oleh Kementerian Kesehatan RI 2014. Pengecatan Basil Tahan Asam Metode Ziehl Neelsen dengan zat peluntur Asam Alkohol sangat penting dengan konsentrasi yang cukup, demi mendapatkan hasil yang akurat dan teliti.

\section{KESIMPULAN}

Berdasarkan hasil penelitian maka dapat disimpulkan bahwa konsentrasi asam alcohol yang digunakan dalam pewarnaan BTA metode Ziehl Neelsen sangat berpengaruh terhadap hasil pemeriksaan BTA.

\section{SARAN}

Penggunaan konsentrasi 3\% sudah sangat sesuai dengan standar IUALTD yang ditetapkan. Untuk peneliti selanjutnya dapat menelti tentang variasi pemanasan dalam menentukan pemeriksaan BTA Metode Ziehl Neelsen

\section{UCAPAN TERIMA KASIH}

Diucapkan terima kasih Kepada petugas laboratorium yang telah banyak membantu dalam terlaksananya penelitian ini. Terkhusus kepada pihak-pihak yang telah banyak membantu terlaksananya penelitian ini.

\section{DAFTAR PUSTAKA}

Alvinova Adriyani, 2016.Gambaran Hasil Perbandingan Pemeriksaan Mikroskopis. Basil Tahan Asam Dengan Variasi 
Carbol Fuchsin dan Methyelen Blue.

Fujiki, A. 2009. Preparasi Sediaan Dahak BTA yang Baik, Panduan Petugas Laboratorium di Unit Pelayanan Kesehatan. Jakarta : Kemenkes

Kementerian Kesehatan RI, 2017. Petunjuk Teknis Pemeriksaan TB Menggunakan Tes Cepat Molekuler. Jakarta : Kemenkes

Nizar. M, 2017. Pemberantasan Dan Penanggulangan Tuberculosis Edisi Revisi. Yogyakarta: Gosyen Publishing.

Ramlah,2016.perbandingan hasil pemeriksaan basil tahan asam BTA menggunakan metode ziehl Neelsen dan metode KinyounGabbet pada penderita Tuberculosis paru.bbkpm.Makassar

WHO,2018.Kemenkes Percepat Atasi Tiga Masalah.depkes 
Tabel 1. Interpretasi Hasil Pewarnaan Basil Tahan Asam

\begin{tabular}{|c|c|c|}
\hline Apa yang Terlihat & Hasil & Apa yang di tuliskan \\
\hline 1.Tidak ditemukan & & \\
\hline $\begin{array}{l}\text { BTA dalam } 100 \\
\text { lapangan pandang }\end{array}$ & Negatif & Neg \\
\hline $\begin{array}{l}\text { 2. ditemukan 1-9 BTA } \\
\text { dalam } 100 \text { lapangan } \\
\text { pandang (tuliskan jml } \\
\text { BTA yang } \\
\text { ditemukan) }\end{array}$ & scanty & Tulis jumlah BTA \\
\hline 3. ditemukan $10-99$ & & \\
\hline $\begin{array}{l}\text { BTA dlm } 100 \text { lapang } \\
\text { pandang }\end{array}$ & +1 & +1 \\
\hline 4. ditemukan $1-10$ & & \\
\hline $\begin{array}{l}\begin{array}{l}\text { BTA setiap } 1 \text { lapang } \\
\text { pandang } \\
\text { minimal }\end{array} \text { (periksa } \\
\begin{array}{l}\text { pandang) } \\
\text { papang }\end{array}\end{array}$ & +2 & +2 \\
\hline $\begin{array}{l}\text { 5. ditemukan } 10 \text { BTA } \\
\text { dalam } 1 \text { lapang } \\
\text { pandang (periksa } \\
\text { minimal } 20 \text { lapang } \\
\text { pandang) }\end{array}$ & +3 & +3 \\
\hline
\end{tabular}

Tabel 2. Distribiusi konsentrasi asam alcohol terhadap hasil pewarnaan bakteri

\begin{tabular}{|c|c|c|c|c|}
\hline \multicolumn{5}{|c|}{ tahan asam } \\
\hline $\begin{array}{l}\text { Kode } \\
\text { Sampel }\end{array}$ & $\begin{array}{l}\text { Sampel } \\
\text { Positif }\end{array}$ & Konsentrasi & $\begin{array}{c}\text { Hasil } \\
\text { Pewarnaan }\end{array}$ & Interpretasi \\
\hline \multirow{7}{*}{ A } & \multirow{7}{*}{+1} & 1 & 3 & $\begin{array}{l}\text { Bakteri tidak jelas } \\
\text { dan latar belakang tidak } \\
\text { jelas }\end{array}$ \\
\hline & & 2 & 4 & $\begin{array}{l}\text { bakteri dan latar belakang } \\
\text { jelas }\end{array}$ \\
\hline & & 3 & 2 & $\begin{array}{l}\text { Bakteri jelas dan latar } \\
\text { belakang jelas }\end{array}$ \\
\hline & & 4 & 3 & $\begin{array}{l}\text { Bakteri tidak jelas } \\
\text { dan latar belakang tidak } \\
\text { jelas }\end{array}$ \\
\hline & & 5 & 1 & $\begin{array}{l}\text { Bakteri dan latar } \\
\text { belakang tidak jelas }\end{array}$ \\
\hline & & 1 & 3 & $\begin{array}{l}\text { Bakteri tidak jelas } \\
\text { dan latar belakang tidak } \\
\text { jelas }\end{array}$ \\
\hline & & 2 & 4 & $\begin{array}{l}\text { bakteri dan latar belakang } \\
\text { jelas }\end{array}$ \\
\hline
\end{tabular}




\begin{tabular}{|c|c|c|c|c|}
\hline \multirow[t]{4}{*}{ B } & +2 & 3 & 4 & $\begin{array}{l}\text { bakteri dan latar belakang } \\
\text { jelas }\end{array}$ \\
\hline & & 4 & 3 & $\begin{array}{l}\text { Bakteri tidak jelas } \\
\text { dan latar belakang tidak } \\
\text { jelas }\end{array}$ \\
\hline & & 5 & 1 & $\begin{array}{l}\text { Bakteri dan latar } \\
\text { belakang tidak jelas }\end{array}$ \\
\hline & & 1 & 3 & $\begin{array}{l}\text { Bakteri tidak jelas } \\
\text { dan latar belakang tidak } \\
\text { jelas }\end{array}$ \\
\hline \multirow{4}{*}{$\mathrm{C}$} & +3 & 2 & 4 & $\begin{array}{l}\text { bakteri dan latar belakang } \\
\text { jelas }\end{array}$ \\
\hline & & 3 & 4 & $\begin{array}{l}\text { bakteri dan latar belakang } \\
\text { jelas }\end{array}$ \\
\hline & & 4 & 3 & $\begin{array}{l}\text { Bakteri tidak jelas } \\
\text { dan latar belakang tidak } \\
\text { jelas }\end{array}$ \\
\hline & & 5 & 1 & $\begin{array}{l}\text { Bakteri dan latar } \\
\text { belakang tidak jelas }\end{array}$ \\
\hline
\end{tabular}

Keterangan:

Interpretasi: Positif $1=1$, Positif $2=2$, Positif $3=3$

Konsentrasi: $1 \%=1,3 \%=2,6 \%=3,9 \%=4,12 \%=5$

Hasil pewarnaan:

$1=$ bakteri dan latar belakang tidak jelas,

$2=$ Bakteri jelas dan latar belakang tidak jelas,

3 = Bakteri tidak jelas dan latar belakang jelas,

$4=$ Bakteri dan latar belakang jelas

Tabel 3. Tabel uji Saphiro-Wilkocson

\section{Interpretasi Sig-}

\begin{tabular}{llll}
\hline Hasil & Positif 1 & 0. & 814 \\
Pewarnaan & Positif 2 & 0.146 \\
& Positif 3 & 0.146 \\
\hline
\end{tabular}

Tabel 4. Post Hoc test

\begin{tabular}{cccc}
\multicolumn{2}{c}{$\begin{array}{c}\text { Konsentrasi } \\
\text { Asam Alkohol }\end{array}$} & Sig & $\begin{array}{c}\text { mean } \\
\text { Difference }\end{array}$ \\
\hline \multirow{2}{*}{$1 \%$} & $3 \%$ & 0.217 & -1.00 \\
$6 \%$ & 0.926 & -0.33 \\
$9 \%$ & 1.000 & 0.00 \\
$12 \%$ & 0.009 & 2.00 \\
$1 \%$ & 0.217 & 1.00 \\
\hline
\end{tabular}




\begin{tabular}{cccc}
\hline & $6 \%$ & 0.546 & 0.67 \\
$3 \%$ & $9 \%$ & 0.217 & 1.00 \\
& $12 \%$ & 0.001 & 3.00 \\
& $1 \%$ & 0.926 & 0.33 \\
$6 \%$ & $3 \%$ & 0.546 & -0.67 \\
& $9 \%$ & 0.926 & 0.33 \\
& $12 \%$ & 0.004 & 2.33 \\
& $1 \%$ & 1.000 & 0.00 \\
$9 \%$ & $3 \%$ & 0.217 & -1.00 \\
& $6 \%$ & 0.926 & -0.33 \\
& $12 \%$ & 0.009 & 2.00 \\
& $1 \%$ & 0.009 & -2.00 \\
$12 \%$ & $3 \%$ & 0.001 & -3.00 \\
& $6 \%$ & 0.004 & -2.33 \\
& $9 \%$ & 0.009 & -2.00 \\
\hline
\end{tabular}

